Theories \& Applications, the International Edition

Printed Version : (ISSN 2090-5262)

Online Version : (ISSN 2090-5270)

November 2014, Volume 4, No. 3 Pages (15 - 21)

\title{
Kinematics' Indicators of Learning Stages of the Methods of Technical Performance in Long Jump Sport.
}

\section{Dr. Omar Mohammed Labibe Hassan}

Assistant professor, sport kinesiology dep., faculty of physical education - Minia University, Egypt.

\section{Dr. Mohammed Soliman Mahmoud Hussein}

Assistant professor, sport kinesiology dep., faculty of physical education - Minia University, Egypt.

\section{Dr. Ranya Mohammed Said Hassan}

Assistant professor, curriculum and teaching methods dep., faculty of physical education-Minia University, Egypt.

\begin{abstract}
The research has aimed at designing three educational programs in order to learn long jump skill in athletics sport which are: sail method, hanging method and walking in air for one and half step method, then identifying the kinematics indicators (displacement-speed-wheel) of technical performance of the three methods at the end of every stage which are (primary compatibility, good compatibility, perfection and the mechanism). The experimental and descriptive methods have been followed using cinematographic analysis on a sample consisted of 30 first grad students of the faculty of physical educationMinia University, divided into three equal experimental groups. Observation, physical tests and experts`opinion were the most important means of data collecting. Results has shown the length of time of motor learning stage and the increasing of the kinematics variables values and the digital level of walking in air method then hanging method and finally sail method. The result has confirmed also, variables of movement of centre of gravity of the body point, are the most important point of the anatomical points and the kinematics indicators, which used to identify or evaluate learning stages of technical performance that have been studied.
\end{abstract}

\section{Introduction:}

$\mathrm{A}$ thletics is the mother and the bride of the sport's games because of having many advantages such as, power, multiplicity of competitions, variety of performance and motion techniques from running to throwing and jumping so it is one of the most interesting and exciting sports such as its signal express (powerfulfastest-highest), all of these achieved in the Long jump competition, which had a super care from the researchers and specialists in spite of this care, it still needs more studying and care to reach the sportive impression by the three known performance methods which they are, squatting, attaching, walking in the air ( space).The priority of each method differs from each player to the other in accordance with the preference and preparation of each player and also in accordance with the learning stage and the perfection of the player in each method. So it was necessary to increase the concentration and care by the well selection and the quality of teaching the player the needed technical performance which are the essential supports for reaching the best performance levels. Judgment on the quality of performance learning takes place by a self-sensitive method or by a sportive objective method that is the most important because of the high accuracy and not biased and that is by applying the vital mechanism rules on the performance by using some points and essential mechanical variables ( Kinematics' Indicators) that to recognize any stage of the three learning stages ( primary compatibility - good compatibility - fixing and perfection or mechanism ) the player has reached from here we can easy direct the learner the right direction to achieve the needed aim .In this way confirm " Mohamed Brikaa " and " Khayreya ELsukary " 2002, that as soon as knowing the scientific bases of motor learning help the teacher or the trainer to has his correct judgment, in which belong to the learning tools, the period and substance of practice, that prepared him to choose the equal technique and to discover the roots of shortcoming, that may appear in the performance (12:18). Here appears the search issue Throughout the researcher's notes and their specific scientific reading they found rareness in the studies that discussed the possibility of recognizing the motion learning stages (psychomotor) in a mechanical objective method for the Long jump performance methods which made them make this study.

\section{Aim:}

Designing and applying three educational programs of the long jump with the essential methods, the first "squatting", the second "attachment", the third is for walking in the air on the research sample, and recognizing on the :

1-Values of the Kinematics variables of performing the long jump skill with the three methods during the motor Good compatibility- learning stages (primary compatibilityfixing and perfection "mechanism")

2- Kinematics Indicators values , that refers to each stage of the three learning stages, which equal average of the 
variable value of performing long jump skill for the three search methods the cure Kinematics variables ,that have been studied ,include Enter speed, loss of Horizontal speed, Upgrade angle-enter, Upgrade angle-exit ,Upgrading distance enter, Upgrading distance exit, Scurrying speed, Scurrying angel, Height of starting point , Height of flying distance, Height of flying from earth , Landing angel, Landing distance ,Upgrading time ,Flying time ,Landing time, Full performance time, Full performance time, the total measured distance .

\section{Method:}

The experimental and descriptive methods have been followed on a sample, which has been chosen by an intentional way from the first year students of the faculty of the physical education - El Mini University for the study year 2012/2013 for those who haven't learned the long jump skill before the age of 17-19 years old . which is thirty players has been divided into three equal experimental groups, the first group is to learn the squatting method, the second is to learn the attachment method, and the third is to learn the walking in the air method. The equivalence had been found between them as so :

Table (1)

Analysis of variance for the three research groups in the age changes, physicall, and mental $(\mathrm{n}=\mathbf{3 0})$

\begin{tabular}{|c|c|c|c|c|c|c|c|}
\hline Variables & 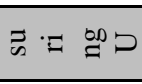 & $\begin{array}{c}\text { Variation } \\
\text { Source } \\
\end{array}$ & 0 䒕宅 & $\begin{array}{c}\text { Squares } \\
\text { Total } \\
\end{array}$ & $\begin{array}{l}\text { Squares } \\
\text { Average } \\
\end{array}$ & 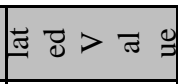 & $\begin{array}{c}\text { Statistical } \\
\text { Significance }\end{array}$ \\
\hline \multirow{2}{*}{ Age } & \multirow{2}{*}{ year } & Between group & 2 & 59.53 & 29.62 & \multirow{2}{*}{0.51} & \multirow{2}{*}{$\begin{array}{c}\text { Not } \\
\text { significance }\end{array}$} \\
\hline & & Inside group & 27 & 1561.20 & 57.82 & & \\
\hline \multirow{2}{*}{ Length } & \multirow{2}{*}{$\mathrm{cm}$} & Between & 2 & 3.19 & 1.60 & \multirow{2}{*}{0.20} & \multirow{2}{*}{ Not } \\
\hline & & Inside & 27 & 219.00 & 8.11 & & \\
\hline \multirow{2}{*}{ Length } & \multirow{2}{*}{$\mathrm{cm}$} & Between & 2 & 12.69 & 6.35 & \multirow{2}{*}{0.30} & \multirow{2}{*}{ Not } \\
\hline & & Inside & 27 & 571.60 & 21.17 & & \\
\hline \multirow{2}{*}{ Weight } & \multirow{2}{*}{$\mathrm{kg}$} & Between & 2 & 0.03 & 0.02 & \multirow{2}{*}{0.06} & \multirow{2}{*}{ Not } \\
\hline & & Inside & 27 & 7.33 & 0.27 & & \\
\hline \multirow{2}{*}{ Flexibility } & \multirow{2}{*}{ meter } & Between & 2 & 15.12 & 7.56 & \multirow{2}{*}{0.85} & \multirow{2}{*}{ Not } \\
\hline & & Inside & 27 & 240.9 & 8.92 & & \\
\hline \multirow{2}{*}{ speed } & \multirow{2}{*}{$\mathrm{cm}$} & Between & 2 & 0.03 & 0.02 & \multirow{2}{*}{0.07} & \multirow{2}{*}{ Not } \\
\hline & & Inside & 27 & 5.98 & 0.22 & & \\
\hline \multirow{2}{*}{ fitness } & \multirow{2}{*}{ second } & Between & 2 & 0.08 & 0.04 & \multirow{2}{*}{0.04} & \multirow{2}{*}{ Not } \\
\hline & & Inside & 27 & 25.89 & 0.96 & & \\
\hline \multirow[t]{2}{*}{ Compatibility } & \multirow{2}{*}{ second } & Between & 2 & 0.94 & 0.47 & \multirow{2}{*}{0.19} & \multirow{2}{*}{ Not } \\
\hline & & Inside & 27 & 67.94 & 2.52 & & \\
\hline \multirow{2}{*}{ power } & \multirow{2}{*}{$\mathrm{cm}$} & Between & 2 & 4.09 & 2.05 & \multirow{2}{*}{0.45} & Not \\
\hline & & Inside & 27 & 121.70 & 4.51 & & Not \\
\hline intelli & deoren & Between & 2 & 4.09 & 2.05 & $0=15$ & Net \\
\hline 1ілеппенсе & atgiee & Inside & 27 & 121.70 & 4.51 & 0.45 & Not \\
\hline
\end{tabular}

Scheduled value of $(f)$ at level $(0.05)=3.35$

Schedule1 declares that the calculated (f) value less than the scheduled (f) value that means there is no statistical significance difference between the three groups of the research which means that they are equal in these variables. The tests have been performed in17, 19/3/ 2013 and it divided into : Physical tests : test of tendency on the box to measure the flexibility of the backbone muscles and the back of the thighs, running test of 30 meters to measure the transition speed, rebound running test to measure the fitness, numbered circles test to measure the neural and muscular compatibility, wide bounce of fixing test to measure the muscular ability of the legs (14:346, 381, 409, 425,399), and Mental Tests : Cattle Test for General Intelligence (1-7)

\section{- Suggested Programs Implementation :}

The first program had been implemented in the period from 24-3 to 16-4-2013, the second program from 24-3 to 23-4, the third program from 24-3 to 30-4-2013 all of them were having two courses (two educational units) per week, each unit time 60 sixty minutes in accordance with that the first program implementation took 4 weeks of 8 educational units, the second took 5 weeks of 10 educational units, and the third took 6 weeks of 12 educational units . They took in their mind in applying these programs the commitment of 
the course time according to the list of the faculty and the content of the athletics subject of the first year of the faculty.

\section{- Post and between-measurement :}

The first measure or photo for all the groups at the end of the first week on $28 / 3 / 2013$, the second was at the end of the second week on 4/4/2013, the third and final photo of the first group was on $18 / 4 / 2013$ that was at the end of the fourth week, at the end of the fifth on 25/4/2013 was for the second group, at the end of the sixth week on 2/5/2013 was for the third group. All of this was in the sports club on El Mini University at twelve 12 o'clock Am . After performing the suggested educational programs for each group the best three students from each group had been chosen and their technical performance has photographed in average 5 attempt per each student, the best attempt per each student had been chosen and at least the best one per each group ,by this way it has been chosen the best attempt of the best player(ideal) per each group between 15 attempt according to the correct technical aspects and the clarity of the very small details of motor performance and the competence of the attempt for motor analysis, that has done by the experts in athletics ,the best attempt the ideal per each group, has analyzed, after each educational stage to recognize the kinematics indicators, that have been studied in using the following instruments and tools : A Rest meter to measure the length and weight, $3 \mathrm{~T} . \mathrm{V}$ camera Sony brand $(25 \mathrm{mg} / \mathrm{s})$, tripod provided by a water balance, guidelines and control marks which is sticky phosphorous strips at length $25 \mathrm{~cm}$ and width $2.5 \mathrm{~cm}$ put around the body-, 1 measuring unit 3 video cassette tapes $(8 \mathrm{ml})$, a flasher to achieve the coincidence between the photo cameras, a computer attached with it the Motion Analysis Program (3D map). stop watch, a measure strip its length is ten meters, recording applications (personal date of the sample, date related to trials chasing, data of the photocopier locations, measuring the special physical abilities) and the questionnaire of the experts in the suggested educational programs .

\section{- The used statistical instruments :}

Arithmetic Average, Standard Deviation, Analysis of variance in one direction .

\section{Results:}

Table (2)

1) The Values of Kinematics variables for the long jump skill by three methods during the motion learning stages of the search samples groups

\begin{tabular}{|c|c|c|c|c|c|c|c|c|c|c|}
\hline \multicolumn{3}{|c|}{ Squatting } & \multicolumn{3}{|c|}{ Attachment } & \multicolumn{3}{|c|}{ Walking in the Air } & \multirow{2}{*}{$\begin{array}{c}\text { Group and Method } \\
\text { Indicators }\end{array}$} & \multirow{2}{*}{ Stage } \\
\hline Perfection & Good & Primary & Perfection & Good & Primary & Perfection & Good & Primary & & \\
\hline 6.03 & 5.20 & 6.28 & 7.26 & 7 & 7.2 & 6.91 & 7 & 5.89 & Enter speed & \multirow{6}{*}{$\begin{array}{c}\text { Enter } \\
\text { \&upgrade }\end{array}$} \\
\hline $0.46+$ & $0.92+$ & 1.79 & 0.49 & 1.24 & 0.97 - & $0.96-$ & 0.65 - & 0.26 & Horizontal speed loss & \\
\hline 50.66 & 63.18 & 63.18 & 75.79 & 69.10 & 53.41 & 72.60 & 56.73 & 68.81 & Upgrade angle-enter & \\
\hline 75.24 & 63.06 & 57.99 & 59.87 & 66.41 & 71.75 & 71.16 & 71.71 & 69.20 & Upgrade angle-exit & \\
\hline 0.66 & 0.41 & 0.41 & 0.24 & 0.28 & 0.64 & 0.30 & 0.59 & 0.36 & Upgrading distance-enter & \\
\hline 0.28 & 0.53 & 0.65 & 0.61 & 0.53 & 0.33 & 0.40 & 0.38 & 0.45 & Upgrading distance-exit & \\
\hline 6.49 & 6.12 & 4.49 & 6.73 & 5.76 & 6.29 & 5.95 & 6.35 & 5.63 & Scurrying speed & \multirow{3}{*}{ Scurrying } \\
\hline 27.22 & 11.49 & 16.70 & 21.80 & 12.57 & 15.87 & 0.58 & 21.25 & 15.70 & Scurrying angel & \\
\hline 1.06 & 1.03 & 1.03 & 1.06 & 1.22 & 1.01 & 1.18 & 1.17 & 1.18 & Height of starting point & \\
\hline 0.40 & 0.11 & 0.04 & 0.15 & 0.22 & 0.17 & 0.14 & 0.18 & 0.11 & Height of flying distance & \multirow{2}{*}{ Flying } \\
\hline 1.46 & 1.14 & 1.07 & 1.21 & 1.00 & 1.18 & 1.32 & 1.35 & 1.29 & Height of flying from earth & \\
\hline 31.97 & 26.66 & 31.39 & 33.36 & 34.68 & 33.21 & 28.22 & 31.43 & 30.04 & Landing angel & \multirow{2}{*}{ Landing } \\
\hline 1.45 & 1.83 & 2.07 & 2.15 & 2.44 & 1.76 & 1.98 & 1.78 & 1.60 & Landing distance & \\
\hline 0.12 & 0.16 & 0.16 & 0.16 & 0.16 & 0.20 & 0.12 & 0.16 & 0.16 & Upgrading time & \multirow{4}{*}{ time } \\
\hline 0.5 & 0.16 & 0.20 & 0.28 & 0.10 & 0.36 & 0.36 & 0.36 & 0.36 & Flying time & \\
\hline 0.32 & 0.40 & 0.36 & 0.28 & 0.56 & 0.28 & 0.32 & 0.36 & 0.36 & Landing time & \\
\hline 1.04 & 0.76 & 0.76 & 0.68 & 0.72 & 0.8 & 0.80 & 0.88 & 0.88 & Full performance time & \\
\hline 5.13 & 4.30 & 3.76 & 4.73 & 4.40 & 4.16 & 4.45 & 4.33 & 3.95 & Total distance & \\
\hline
\end{tabular}


Shape (2)

Enter speed of the long jump players by the three methods squatting- attachment - walking in the air) during the learning stages

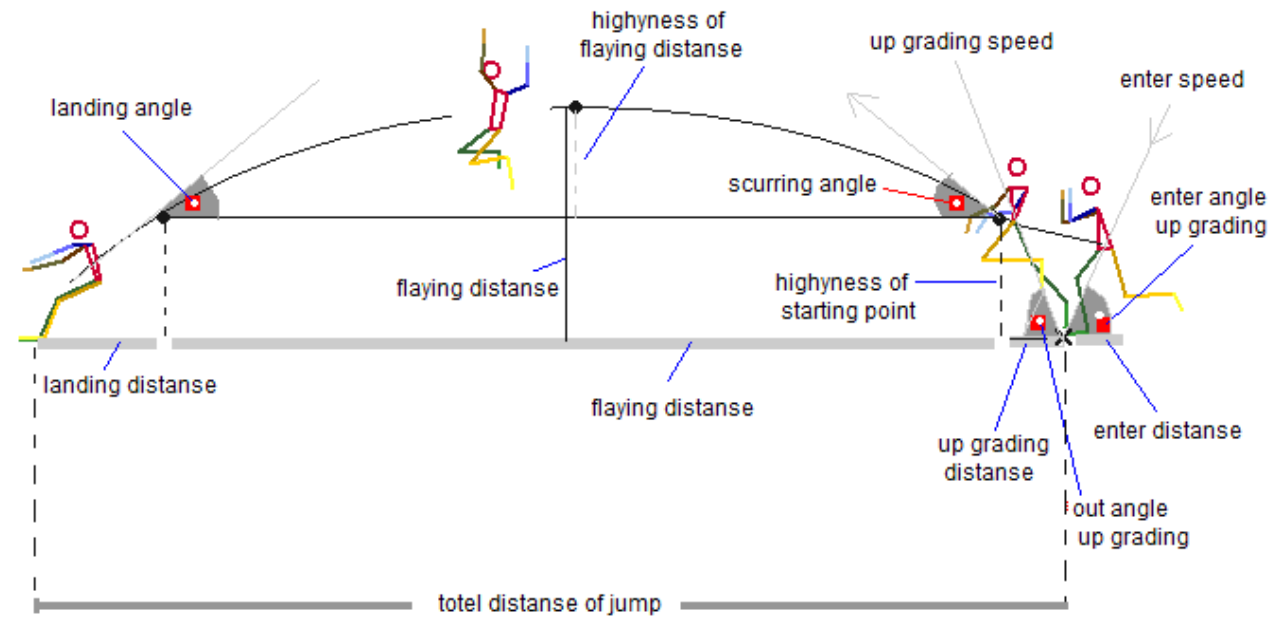

Shape (3)

scurrying speed of the long jump players of the long jump players by the three methods squatting- attachment - walking in the air) during the learning stages

scurring speed

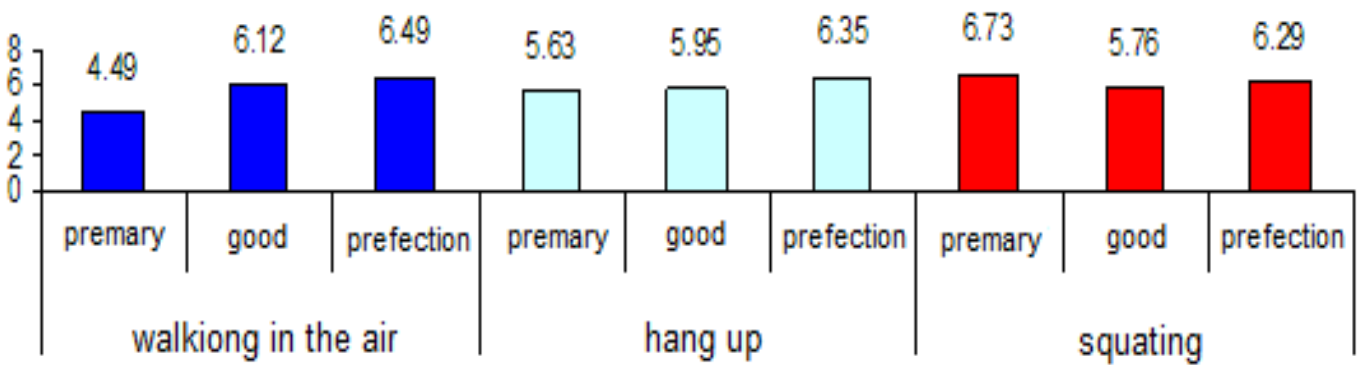

Shape (4)

scurrying angle of the long jump players by the three methods squatting- attachment - walking in the air) during the learning stages

scurriong angle

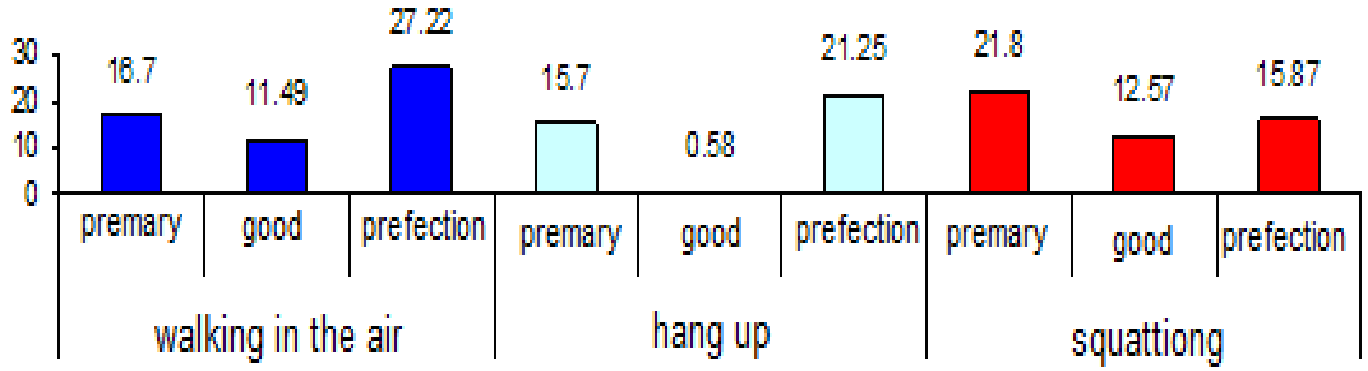


Shape (5)

flying distances of the earth of players of the long jump players by the three methods (squatting- attachment walking in the air) during the learning stages

flying highyness

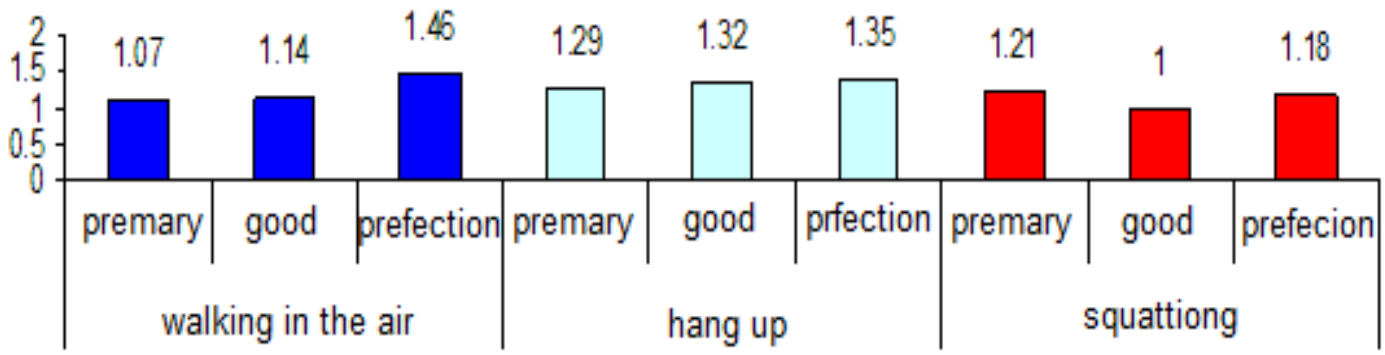

Shape (6)

distance between the center of gravity and the legs in landing of the long jump players by the three methods (squatting- attachment - walking in the air) during the learning stages

distanse between the

c. $g$ and legs in landing

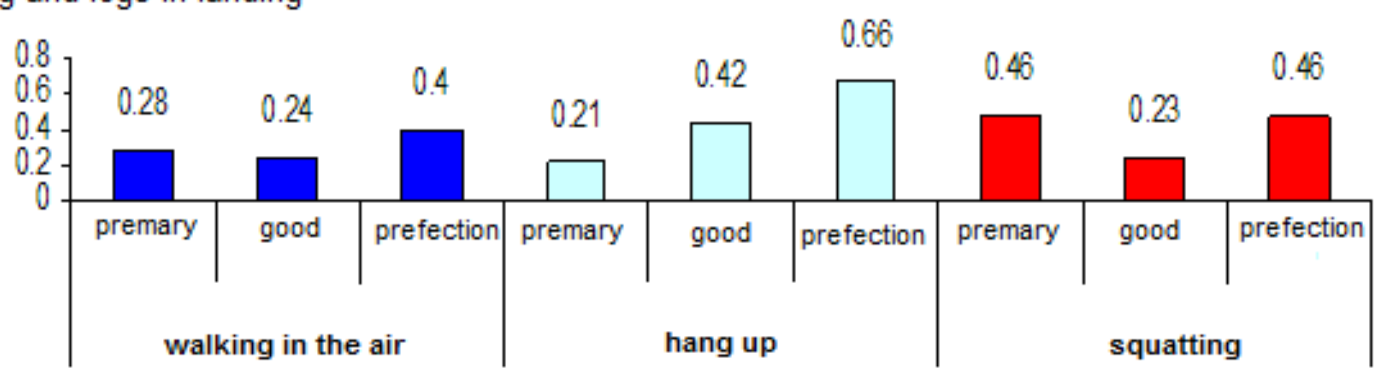

Shape (7)

period of the total performance of the long jump players by the three methods (squatting- attachment - walking in the air) during the learning stages

peroid of the totel

performance

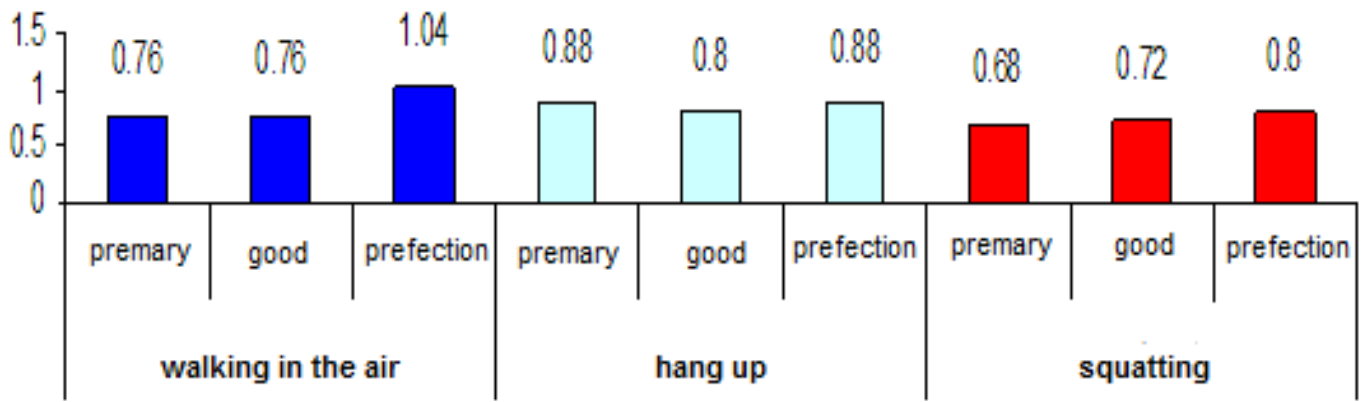


Table( 3)

2) Indicator values (average values of the variables) function kinematic on stage to perform the skill of learning the long jump three ways among a sample search

\begin{tabular}{|c|c|c|c|c|c|}
\hline $\begin{array}{l}\text { Perfection } \\
\text { \&fixing }\end{array}$ & $\begin{array}{c}\text { Good } \\
\text { compatibility }\end{array}$ & $\begin{array}{c}\text { Primary } \\
\text { compatibility }\end{array}$ & Stage & & variable \\
\hline 06.73 & 06.46 & 06.40 & $\mathrm{~m} / \mathrm{s}$ & Enter speed & \multirow{6}{*}{ Enter\& upgrade } \\
\hline-00.32 & -00.33 & -01.01 & $\mathrm{~m} / \mathrm{s}$ & Horizontal speed loss & \\
\hline 66.35 & 63.03 & 61.80 & Angle & Upgrade angle-enter & \\
\hline 68.76 & 67.06 & 66.31 & Angle & Upgrade angle-exit & \\
\hline 00.40 & 00.43 & 00.47 & Meter & Upgrading distance-enter & \\
\hline 00.43 & 00.46 & 00.48 & Meter & Upgrading distance-exit & \\
\hline 06.39 & 06.08 & 05.47 & $\mathrm{~m} / \mathrm{s}$ & Scurrying speed & \multirow{3}{*}{ scurrying } \\
\hline 16.33 & 16.09 & 15.10 & Angle & Scurrying angel & \\
\hline 01.14 & 01.10 & 01.07 & Meter & Heightof starting point & \\
\hline 00.23 & 00.11 & 00.02 & Meter & Heightof flying distance & \multirow{2}{*}{ flying } \\
\hline 01.33 & 01.18 & 01.16 & Meter & Heightof flying from earth & \\
\hline 31.55 & 31.18 & 30.92 & Angle & Landing angel & \multirow{2}{*}{ landing } \\
\hline 02.02 & 01.86 & 01.81 & Meter & Landing distance & \\
\hline 00.13 & 00.16 & 00.19 & Second & Upgrading time & \multirow{4}{*}{ time } \\
\hline 00.27 & 00.22 & 00.09 & Second & Flying time & \\
\hline 00.44 & 00.33 & 00.31 & Second & Landing time & \\
\hline 00.84 & 00.81 & 00.79 & Second & Full performance time & \\
\hline 04.77 & 04.34 & 03.96 & Meter & \multicolumn{2}{|c|}{ Total distance } \\
\hline
\end{tabular}

It is obvious in the previous schedule 2, 3 and figure (1-7) that the kinematics variable values and the kinematics indicators values (averages of variables values) it differs from an educational stage to another in the positive direction that refer to improving the education process in the three methods of bounce and each learning stage has a specific rate for these variables this rate indicates on reaching the student to this stage that is as mentioned in all Kinematics variables and indicators in the two schedules, owes this to the quality of preparation and implementing the suggested educational programs and to the regularity of the search sample in the educational units. Here indicate " Brieg . w " 1995, and " jose manuel " 1992 that the most important elemant to reach at high performed level in athletics is the good quality of planning and preparing and carrying out the educational programs ,observance of the correct scientific bases such as continuity, train, suitable load and the individual difference in these programs ( 6:148) (7:83). and to attachment of the educational process with these indicators from the point of period and time of transition from an educational unit to another in all sides and details of the educational units, these indicators were a good standard to direct the educational process from a stage to another to reach to the mechanism stage in performing, which consider the highest aim for educational process, in athletics field general and in long jump sepial. Here confirm " Ahmed Elian " 2009, Bridgett ,L.Galloway ,M ., that the most important kinematics indicator that affected in achieving the digital level of technical performance for long jump are scurrying speed and scurrying angle ,the heightof centre of gravity of the body in starting out moment as a conclusion of speed approaching and the power and speed of upgrade ,they confirmed also,the walking in air method is the best technique for long jump ,then it consider an extention of running process and complete it $(3: 4)(7: 77)$.in this way indicate " Bastawisy Ahmed " 1997 and "Seyfarth.A."," Blickhan .R" 2000 that methods of long jump different between each other, in the difficulty grad of performance and the needed period for learning to reach to the perfection (mechanism), which demand awareness and perseverance from the teacher or the trainer to control the performance of the learner and to direct him to the correct track (5:300) (15: 743 )

\section{Conclusions:}

- the best kinematics variables of the performance methods of the long jump , was in the perfection stage then good compatibility later the primary compatibility and on their head the walking in the air method then squatting .

- The most important Kinematics indicators (average of variables) that shows the educational stages (Primary compatibility - Good compatibility fixing and perfection "mechanism") to perform the long jump skill by the three methods (squattingattachment - walking in the air) for the search sample that represented in (speed, angle, distance, 
and time) enter and quit of upgrading, scurrying point, flying path, landing path and that for the center of body gravity) in each educational stage of the different performance methods at the rate that mentioned in schedule 3 .

- Kinematics indicators that are under study is at high efficiency in improving the motion learning operation of the long jump by the three methods that have been applied on the search sample.

\section{Recommendations:}

- Take in account the individual differences in between the learners in the kinematics variables values of performing the long jump skill by the three methods (squatting-attachment - walking in the air) during the different educational stages (Primary compatibility - Good compatibility - fixing and perfection "mechanism") About the period of time needed to reach these values in each educational stage.

- The interest of the Kinematics indicators in (speed, angle, distance, and time) enter and quit of upgrading, scurrying point, flying path, landing path and that for the body as basic criteria to know or judge on the learning stages that the learner or the group reach in the technical performance of the long jump skill by the three learned methods )

- To concentrate on the Kinematics indicators that under study as an important base for improving the learning operation in long jump skill by the three learned methods.

\section{References:}

1. Ahmed Abdel Aziz Salama, Ahmed Abdel Salam Abdel Ghaffar: Cattell testing for intelligence, the Arab Renaissance House, Cairo, 1970

2. Ahmed Saad El Din Omar: improved speed approaching losses and its impact on some variables kinematic to contest the long jump, Research Encyclopedia physical education and sports in the Arab World in the twentieth century, c 3, Curriculum Publishing and Distribution, Amman, 2006.

3. Ahmed Said Elian: the kinematic properties of the two phases of upgrading and aviation in the long jump way walking in the air, Unpublished Master Thesis, Faculty of Physical Education - Minia University, 2009.

4. Ammar Ali al-Naimi: relationship some variables Albayukinmetekih for the last three steps from the approximate Running and stage of advancement of the level of achievement of the long jump unpublished Ph.D. thesis, Faculty of Physical Education, Mosul University, 2001.
5. Bastawisy Ahmed Bastawisy: track and field competitions (education - Technique - Training), the Arab Thought House, Cairo, 1997.

6. Berg, W. and Nancy, $L$ : Akinematic profile of the Approach Run of Novice Long Jumper . Journal of Applied Biomechanics , $11 ; 137$-154,1995 .

7. Bridgett ,L.Galloway ,M ., Linthorne ,N ; The Effect of Run -Up Speed on Long Jump Performance .International Symposium on Biomechanics in Sports .XX ,76 -84,2002 .

8. Jose Manuel steroid: the foundations and principles of education and sports training in athletics, translation Osman Mahmoud Fathi lifted, the International Federation of Athletics, Center for Regional Development, Cairo, 1992.

9. Kelany Hashim Adnan, Ahmed paid Jihad: distance approaching and some kinematic variables as an indicator of the completion of the digital distance jump to the emerging long jump, studies, Educational Sciences, Volume 34, Issue 1, 2007.

10. Linthorne,N.Guzaman,M and Brigdett, $L$; The optimum Take Off Angle in Long Jump .International Symposium on biomechanics in sports .XX , 122-126, 2002 .

11. Mehdi Kazim Ali: "Study of some mechanical variables and their impact on the completion of the long jump, Master Thesis, University of Baghdad, Iraq, 1990.

12. Mohamed Jabber Briva, charitable Ibrahim : diabetes fundamental principles of bio-mechanics in the field of sports, facility knowledge, Alexandria, 2002.

13. Mohamed Saad Hantoush: "Analytical study of some variables Albyukintekah and Albyukinmetekih in the long jump," unpublished message, Faculty of Physical Education, University of Mosul, 2010

14. Mohamed Sobhi Hassanein: Measurement and Evaluation in Physical Education, Part I, 4th Floor, Arab Thought House, Cairo, 1999.

15. Seyfarth, A. ,Blickhan, $\mathbf{R}$.and Van Leeuwen ,J .L ,Optimum take off techniques and muscle design for Long jump .Journal of Expermental Biology , 203 . $740-747,2000$.

16. Talha Hussein Hossam Religion: the principles of scientific diagnosis of movement "of the Arab Thought House, Cairo, 1994.

17. Wadih Yassin al-Tikriti, Samir hanging Hashemi: an index to evaluate the function of power - time in various sports events, Journal of Education and Learning, VolumeVINumber20, 2000 
